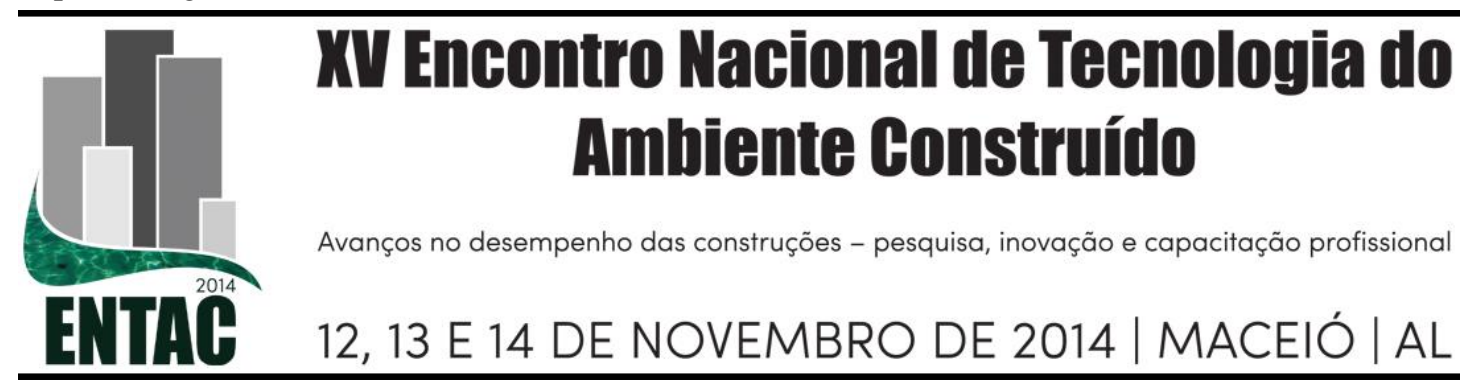

\title{
RESULTADOS DE PESQUISAS CIENTÍFICAS E DISCUSSÕES SOBRE CONFORTO AMBIENTAL URBANO EM SALVADOR / BA
}

\author{
SOUZA, Sandra Helena Miranda de (1); VIEIRA, Carolina Nascimento (2); \\ PAIXÃO, Rosevânia Cerqueira da (3) SOUZA, Danilo Fortuna M. (4); \\ DELGADO, Juan Pedro Moreno (5); MIRANDA, Sílvia Camargo F. (6)
}

(1) UFBA, e-mail: sandramiranda08@gmail.com (2) UFBA, e-mail: carolinanv@ufba.br, (3) UFBA, email: anepaixao@gmail.com, (4) AUDIUM e UFBA, e-mail: danilo@audium.com.br, (5) UFBA, e-mail: jpyupi@yahoo.com.br, (6) UFBA, e-mail: silviamiranda12@gmail.com

\begin{abstract}
RESUMO
O presente trabalho possui objetivo de registrar os resultados de três pesquisas ocorridas na Cidade de Salvador, apresentados no "Ciclo de Palestras Sobre Conforto Ambiental Urbano", bem como as conclusões de discussões promovidas neste evento, realizado pelo Laboratório de Conforto Ambiental da FAUFBA, nos dias 08, 09, 15 e 16 de janeiro de 2014. As pesquisas ocorridas verificaram as condições dos confortos: térmico, acústico e ergonômico da população da cidade. O evento que proporcionou as explanações dos pesquisadores atraiu um público formado por profissionais, representantes do poder público e estudantes interessados na discussão e nos respectivos resultados. A metodologia adotada para elaboração deste artigo consistiu da junção dos resultados obtidos pelas pesquisas apresentadas pelos pesquisadores e discutidas no evento. O estudo sobre conforto térmico constou de pesquisa exploratória quanto à percepção térmica em duas áreas abertas urbanas, para delimitada faixa etária da população; o estudo sobre conforto acústico constou de mapeamento acústico do ruído de tráfego rodoviário de um trecho do Bairro Imbuí; o estudo sobre o conforto ergonômico constou da identificação e avaliação de fatores associados à microacessibilidade que interferem no deslocamento de pedestres, ciclistas e pessoas com deficiências físicas, em uma estação de transporte público e seu entorno. De forma geral, percebeuse, que, os resultados das pesquisas revelam o não atendimento aos limites satisfatórios para o conforto humano dos indivíduos que utilizam as áreas estudadas na cidade, bem como aos parâmetros normativos, legislativos e de percepção humana para os referidos confortos. As principais contribuições de pesquisas dessa natureza, bem como a promoção de eventos que propiciem discussões, envolvem: a valorização de pesquisas científicas que mensurem a satisfação dos indivíduos e a difusão do conhecimento para a população acerca da qualidade de vida urbana ao qual todos estão submetidos.
\end{abstract}

Palavras-chave: Discussão, Conforto Ambiental Urbano, Ciclo de Palestras, Salvador/BA.

\begin{abstract}
This study has aimed to record the contributions resulting from the "Cycle of Conferences on Urban Environmental Comfort", promoted by the Laboratory of Environmental Comfort, Faculty of Architecture $U F B A$, on January $08^{\text {th }}, 09^{\text {th }}, 15^{\text {th }}$ and $16^{\text {th }}, 2014$. It was presented at this event researches that addressed environmental comfort: thermal, acoustic and ergonomic in the city of Salvador/BA; and fostering discussion between the presence of professionals, government representatives and students in these fields on the results presented and issues related to the urban environment. The methodology used to prepare this article consisted of recording and transcribing the results presented and discussions conducted by debaters. The study on thermal comfort consisted of exploratory research concerning the thermal perception in two urban open spaces, for a given age of the population; the acoustical study consisted of the mapping of road traffic noise at the Imbui district; the study of ergonomic comfort consisted of the identification and evaluation of associated micro accessibility that interfere with the movement of pedestrians, cyclists and people with disabilities, in a public transport station and its surroundings.
\end{abstract}


Overall, it was realized that the results of the research reveal noncompliance with satisfactory limits for human comfort of individuals who use the studied areas in the city, and the consecutive regulatory and legislative parameters for such comforts studied. The main contributions of such events, and also the said event in Salvador, were: the importance of fostering scientific research of these natures, as well as, promoting the dissemination of knowledge to the participating public on matters related to the quality of urban environmental comfort, to which all are subjected.

Keywords: Discussion, Urban Environmental Comfort, Cycle of Presentatios, Salvador/BA.

\section{INTRODUÇÃ̃O}

A iniciativa de escrever esse presente artigo surgiu a partir da necessidade de se registrar os resultados e as conclusões obtidas no Ciclo de Palestras Sobre Conforto Ambiental Urbano, que teve como objetivo discutir as condições dos confortos: térmico, acústico e ergonômico que a população residente em Salvador está submetida. Para a avaliação quanto às condições dos confortos, recorreram-se às leis e Normas que abordam cada tema, bem como os parâmetros de opinião quanto à percepção humana.

\section{PESQUISAS APRESENTADAS E SEUS MÉTODOS}

\subsection{Para a avaliação do Conforto Térmico}

Nas últimas décadas, as grandes cidades brasileiras se ergueram resultando grandes aglomerações de edifícios altos e extensas áreas de superfícies pavimentadas e asfaltadas. A falta de planejamento integrado entre construções e elementos vegetais no espaço urbano percorrido pelo indivíduo em seu cotidiano tem resultado em aumento das temperaturas, colaborando para a insatisfação térmica com o ambiente construído, especialmente em alguns horários de maiores taxas de radiação solar. É possível se perceber o quão verdadeira é a consideração de Chandler (1970), quanto às influências da urbanização aos fluxos energéticos na camada atmosférica, camada de ar vivenciada pelo indivíduo. O referido autor afirma que o balanço energético que ocorre na camada atmosférica pode sofrer alterações irreversíveis de suas propriedades naturais, à medida que o território sofra extensiva descaracterização, com pavimentações e edificações (CHANDLER, 1970).

A pesquisa que investigou a percepção térmica da população, residente há mais de 01 (um) ano em Salvador, limitou-se aos indivíduos entre a faixa etária de 20 a 59 anos. As pesquisas de campo ocorreram nos meses de agosto de 2009, outubro de 2009, janeiro de 2010 e maio de 2010; totalizando-se 1.056 questionários válidos e atendendo ao nível de confiança de $95 \%$ para a faixa etária considerada (padrão escolhido através das faixas etárias do IBGE para contagem da população). As áreas abertas urbanas adotadas foram duas praças: Praça Piedade e Praça Cayru, por possuírem características geomorfológicas distintas entre si, com o intuito de ampliar a representação das áreas abertas da cidade estudada (SOUZA, 2010).

Nos referidos meses de pesquisas de campo, as quantidades das entrevistas se distribuíram equivalentemente, bem como a quantidade de entrevista por área de estudo: $50 \%$ em cada. Quanto aos gêneros: $44 \%$ de entrevistas com o gênero feminino e $56 \%$ com o gênero masculino. Nos estudos desenvolvidos, observa-se que, em decorrência da intensa e consolidada urbanização na Cidade de Salvador, predominantemente com superfícies porosas em cores de cinza, aliada à escassez de solo natural e com vegetação, especialmente porte arbóreo nos espaços públicos percorridos pelos indivíduos. A população entrevistada encontrara limitações de horários para a estabilização de seus balanços térmicos, pois as condicionantes "sombra e vento" seriam imprescindíveis para os horários de maiores taxas de radiação solar. 
No Gráfico 1, a seguir, observa-se que $28 \%$ dos entrevistados que estavam à sombra durante e antes da abordagem para a entrevista se consideraram em conforto térmico. Este resultado já seria o esperado, mesmo porque a bibliografia da área de conforto térmico permanentemente relaciona sombra ao conforto térmico para climas quentes; enquanto $18 \%$ dos entrevistados que estavam ao sol durante e antes da abordagem para a entrevista se consideraram dentro das classificações de calor. Este resultado também é esperado, considerando a bibliografia da área de conforto térmico; porém, 39\% dos entrevistados que se encontravam à sombra durante e antes da abordagem para a entrevista se consideraram dentro das classificações de calor (Gráfico 1):

\section{Gráfico 1 - Relação entre Percepção térmica e localização do entrevistado durante e antes da entrevista}

Fonte: Elaborado por Sandra Souza

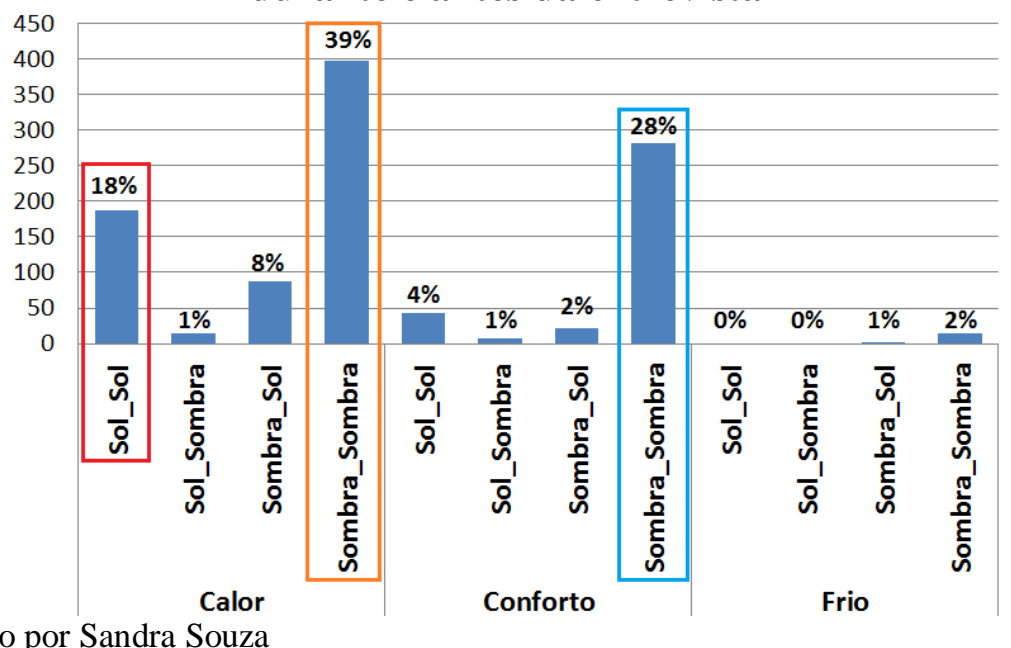

Para o conhecimento das características de algumas variáveis capazes de influenciar os resultados obtidos e destacados no Gráfico 1, recorreu-se às condições de atividade metabólica que estes desenvolviam, horários das entrevistas, vestimentas, em clo, e taxas de radiação solar.

Observando-se o Gráfico 2, a seguir, verifica-se que dos $18 \%$ que se encontravam em desconforto por calor, posicionados ao sol durante e antes à abordagem da entrevista: $3 \%$ estavam sentados, calmos, desenvolvendo atividade metabólica equivalente a $115 \mathrm{~W}$, segundo a Norma ISO 8996 (2004); 6,5\% estavam parados, em pé, desenvolvendo atividade metabólica equivalente a $125 \mathrm{~W}$; e $8,5 \%$ estavam em caminhada casual, desenvolvendo atividade metabólica equivalente a 180W (Norma ISO 8996/2004). Dos $39 \%$ que se encontravam em desconforto por calor, posicionados à sombra durante e antes à abordagem da entrevista: $14 \%$ estavam sentados, calmos, desenvolvendo atividade metabólica equivalente a 115W, segundo a Norma ISO 8996 (2004); 15\% estavam parados, em pé, desenvolvendo atividade metabólica equivalente a $125 \mathrm{~W}$; e $10 \%$ estavam em caminhada casual, desenvolvendo atividade metabólica equivalente a 180W (Norma ISO 8996/2004). Dos 28\% que se considerou em conforto térmico, posicionados à sombra durante e antes à abordagem da entrevista: 13\% estavam sentados, calmos, desenvolvendo atividade metabólica equivalente a $115 \mathrm{~W}$, segundo a Norma ISO 8996 (2004); 8\% estavam parados, em pé, desenvolvendo atividade metabólica equivalente a $125 \mathrm{~W}$; e $7 \%$ estavam em caminhada casual, desenvolvendo atividade metabólica equivalente a 180W (Norma ISO 8996/2004). (Gráfico 2):

\section{Gráfico 2: Relação entre Atividade metabólica, Posição do entrevistado e Percepção térmica}




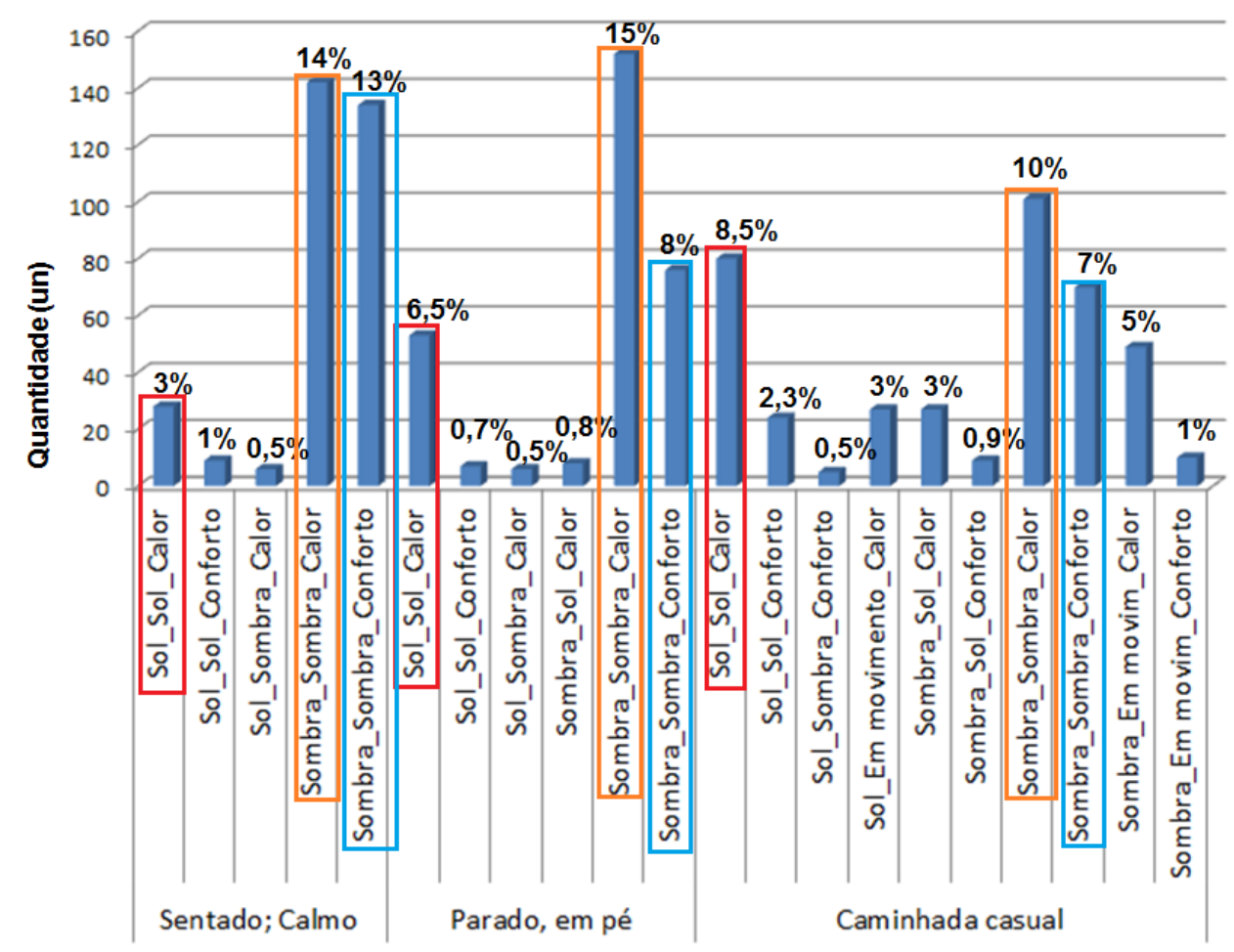

Atividade metabólica, Posição do entrevistadoe Percepção térmica

Fonte: Elaborado por Sandra Souza

No intuito de entender os resultados acima apresentados quanto aos horários pesquisados para os grupos que se destacaram, verificou-se que o grupo de entrevistados que se encontravam durante e antes à entrevista ao sol e com dentro das classificações de calor foram aqueles que foram entrevistados entre 14:00 e 15:00h, com predominância para as entrevistas às 14:00h; enquanto aos entrevistados que se encontravam à sombra durante e antes à entrevista e nas classificações de calor foram entrevistados entre 14:00 e 15:00h, com predominância para as entrevistas às 15:00h; e quanto aos entrevistados que se encontravam à sombra durante e antes à entrevista e em conforto, foram entrevistados entre 15:00 e 16:00h, com predominância para as entrevistas às $15: 30 \mathrm{~h}$.

Observando-se às características de vestimenta desses grupos de entrevistados, percebese que os que estavam posicionados à sombra durante e antes à entrevista e em calor estavam vestidos com o equivalente a 0,3 a 0,5 clo, predominando 0,5 clo para este grupo; e para os dois outros grupos, os posicionados à sombra durante e antes à entrevista: em calor e em conforto, também estavam com vestimentas equivalentes a 0,3 e 0,5 clo, mas com predominância para $0,4 \mathrm{clo}$.

Quando relacionados os referidos grupos às taxas de radiação solar, observa-se que o primeiro, os posicionados ao sol durante e antes à entrevista e em calor estavam submetidos às taxas de radiação solar que variaram entre 350 a $570 \mathrm{~W} / \mathrm{m}^{2}$, com predominâncias em $500 \mathrm{~W} / \mathrm{m}^{2}$; enquanto aos posicionados à sombra durante e antes à entrevista e em calor, naqueles momentos foram medidas taxas de radiação solar entre 200 a $550 \mathrm{~W} / \mathrm{m}^{2}$, com predominâncias em $380 \mathrm{~W} / \mathrm{m}^{2}$; e ao grupo posicionado à sombra durante e antes à entrevista e em conforto, taxas de 180 a $380 \mathrm{~W} / \mathrm{m}^{2}$, com predominâncias em $250 \mathrm{~W} / \mathrm{m}^{2}$.

Dentre inúmeros benefícios oferecidos pela vegetação, sobretudo o porte arbóreo para as grandes cidades, encontram-se a retroalimentação dos lençóis freáticos, a purificação do ar atmosférico, dentre outros. Ainda, o porte arbóreo colabora na redução das taxas 
de radiação solar que atinge a superfície, e ainda pode reduzir até cerca de $6,5^{\circ} \mathrm{C}$ a Temperatura do ar aos fluxos energéticos da camada atmosférica vivenciada pelos indivíduos, através da sombra (SOUZA, 2010), colaborando para o equilíbrio do balanço térmico humano no ambiente, especialmente para climas quentes.

\subsection{Para a avaliação do Conforto Acústico}

Na medida em que a Cidade de Salvador se adensa ao longo das vias de maior fluxo de veículos, maior parcela da população é exposta a elevados níveis de ruído que podem ser intensificados pelas reflexões sonoras sucessivas decorrentes do adensamento das construções lindeiras às vias. A partir do estudo da propagação do ruído de tráfego rodoviário na cidade, é possível evidenciar a inadequação do planejamento viário ou da legislação do uso do solo. Neste intuito, a pesquisa sobre conforto acústico apresenta estudos dos níveis de ruído do tráfego rodoviário de um trecho do Bairro Imbuí (Salvador-BA) por meio da ferramenta de Mapeamento Acústico.

Apresentou-se, no Ciclo de Palestras, alguns métodos adotados neste trabalho, dentre eles: coleta de informações em órgãos públicos e em campo; coleta in loco de dados de fluxo de veículos e registro sonoro; análise e compilação dos dados obtidos para simulação em programa computacional de mapeamento acústico; e um resultado parcial deste trabalho, os Mapas Acústicos do período Diurno, 7h-22h (Figura 1).

As informações georeferenciadas em meio digital, adquiridas em órgãos públicos, tais como informações vetorizadas e rasterizadas (imagens aéreas), foram utilizadas na elaboração e atualização da base cartográfica do mapeamento acústico. Adotou-se a base SICAR/1992 (Sistema Cartográfico da Região Metropolitana de Salvador), complementada com o sistema viário vetorizado da base SICAD/2006 (Sistema Cartográfico e Cadastral do Município de Salvador). Promoveu-se uma atualização quanto às novas edificações construídas após 1992, além de uma modificação viária, finalizada em 2010 na Av. Jorge Amado, importante avenida do bairro e adjacências, além de demais elementos pertinentes à simulação acústica, como muros e vegetação.

A coleta in loco de informações de dados de fluxo da média horária anual de veículos leves e pesados e o registro sonoro foi imprescindível ao desenvolvimento das etapas precedentes ao resultado da Simulação Acústica e formaram o banco de dados que alimentou o programa computacional de mapeamento acústico, CadnaA, Computer Aided Noise Abatement - versão 4.1 (DataKustik), viabilizando mapas acústicos do ruído de longo prazo considerando uma média anual de ruído para todas as vias analisadas. $\mathrm{O}$ conjunto de base de dados da simulação acústica contempla as fontes de ruído, vias de tráfego rodoviário, bem como, todos os objetos e embarreiramentos, edificados ou naturais, que influenciam na propagação sonora do ruído ambiental.

Apresentou-se parte dos produtos finais, que foram obtidos por meio de simulação da propagação sonora no modelo tridimensional desenvolvido no programa CadnaA, que foram: Mapas Acústicos Horizontais, exemplificado na figura 1a, e Verticais (Figuras 1c, 1d, 1e) e visualizações 3D (Figuras 1b, 1f, 1g) correspondentes ao período diurno.

Apresentou-se, também, o resultado de um estudo comparativo entre o mapeamento dos níveis excedentes em relação aos parâmetros da Lei No 5.354 (SALVADOR, 1998) e da NBR 10151 (ABNT, 2000) observados nas Figuras 1f e 1g:

Figura 1 - Mapas Acústicos Lde (período 15 horas - de 7:00 às 22:00h) 


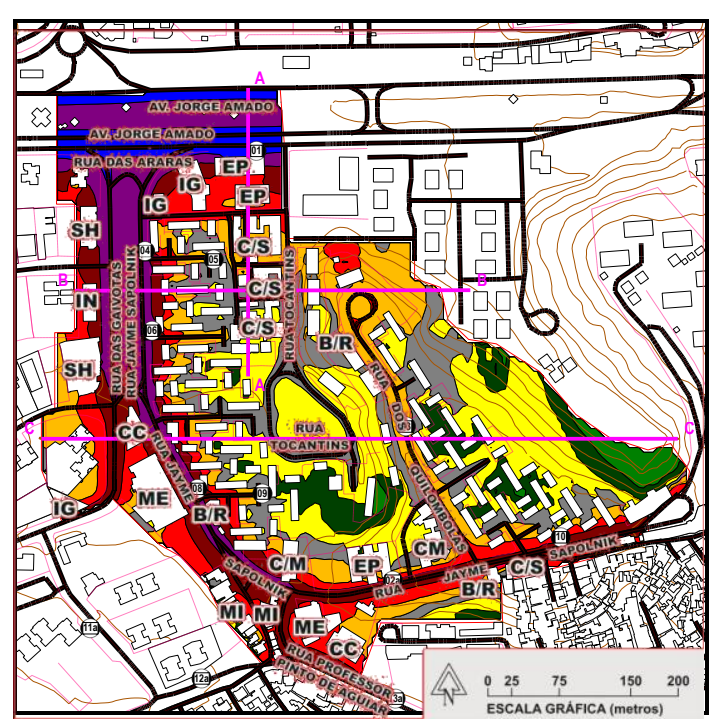

(a) Mapa horizontal: Níveis de Ruído Calculados

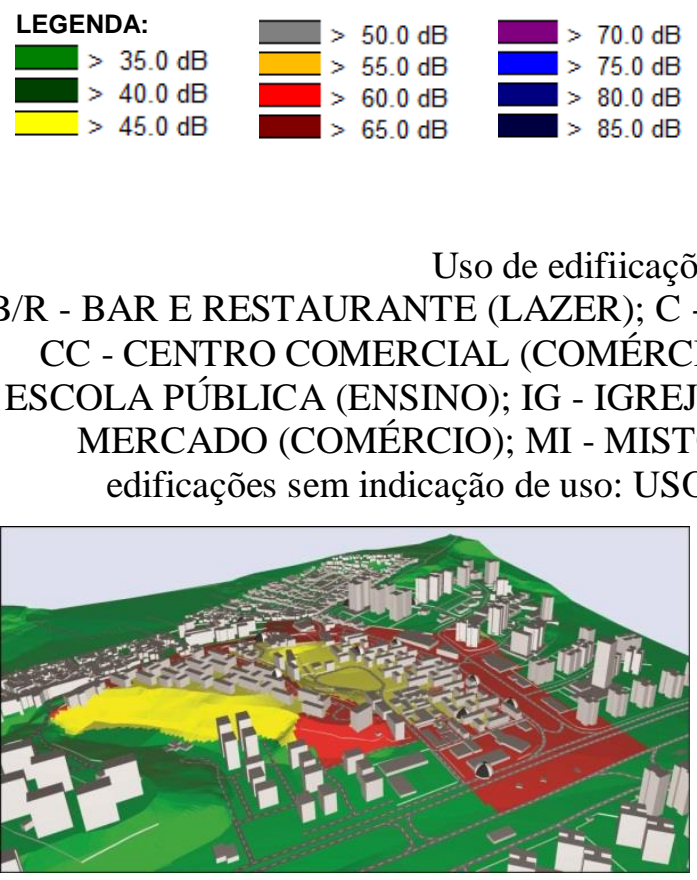

(f) Níveis de Excedência

Fonte: ABNT - NBR 10.151 (ABNT, 2000)

$$
\begin{gathered}
\text { LEGENDA: } \geq 55 \mathrm{~dB} \quad<55 \mathrm{~dB} \\
\text { Parâmetro “Área mista, Predominantemente } \\
\text { residencial” período diurno (7-22h) } \\
\text { Fonte: ABNT, } 2000
\end{gathered}
$$

Fonte: Souza, 2012

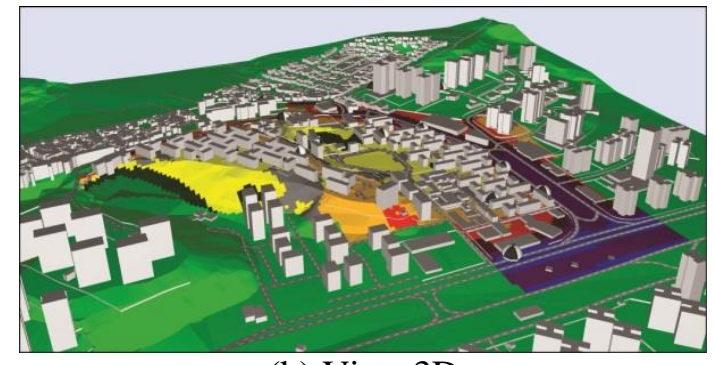

(b) Vista 3D

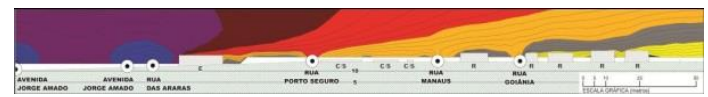

(c) Mapa Vertical A

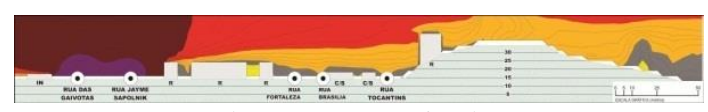

(d) Mapa Vertical B

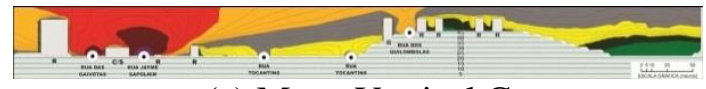

(e) Mapa Vertical C

$\square \quad$ Delimitação Mapa Acústico

Horizontal

Edificações

Mapas Acústicos Verticais “A”, "B”

e "C"

Vias

$$
\begin{aligned}
& \text { Curvas de Nível (5 em } 5 \text { metros) } \\
& \text { Muros }
\end{aligned}
$$

da Área Mapeada:

da Area Mapeada:
COMÉRCIO; C/S - CON

COMÉRCIO E SERVIÇOS;

); CM - CENTRO MÉDICO (SAÚDE); EP- 
arterial, de maior fluxo, estima-se aproximadamente 75dB. Este mesmo nível de ruído incide na fachada de uma escola pública aí localizada, encontrando-se $20 \mathrm{~dB}$ acima do parâmetro de 55dB para "Área mista, predominantemente residencial", estabelecido pela NBR 10151 (ABNT, 2000). Para as demais vias, estimou-se níveis de ruído que variam de $70 \mathrm{~dB}$ a $50 \mathrm{~dB}$. Souza (2012) salienta que a referida norma se apresenta mais restritiva que a Lei Municipal No 5.909 (SALVADOR, 1998), conforme explicitado a partir da comparação dos mapas acústicos das figuras $1 \mathrm{f} \mathrm{e} 1 \mathrm{~g}$.

Ainda segundo Souza (2012), não existem leis ou planos estratégicos de mitigação do ruído proveniente do transporte rodoviário na cidade que estabeleçam condicionantes específicas e eficazes de planejamento urbano no tocante ao ambiente acústico.

\subsection{Para a avaliação do Conforto Ergonômico}

Ao abordar a circulação no espaço urbano, percebe-se que esta vem sendo desenvolvida de maneira desarticulada ou não integrada; e com forte influência dos investimentos ligados às infraestruturas que fomentam apenas a utilização de modos de transportes motorizados, com destaque para a indústria automobilística. As calçadas e passeios, por exemplo, são elementos que deveriam assumir o papel de condicionantes diretos na promoção do deslocamento não motorizado-NM, que de acordo com a VTPI (2010a) incluem as formas de deslocamento a pé e de bicicleta, além de suas variantes, como por exemplo, os transportes de pequeno porte sobre rodas (patins, skates, patinetes, carrinhos de mão, etc.). Mas o que se percebe é que estes espaços estão deixando de ser relevantes, não sendo mais considerados como bens públicos capazes de oferecer segurança e conforto aos indivíduos que circulam nas cidades.

O conforto ergonômico nestes deslocamentos Não Motorizados trata das condições adequadas que permitam que qualquer pessoa, (inclusive com deficiência ou mobilidade reduzida), tenha o direito de chegar "confortavelmente" a qualquer lugar.

Nestas condições, observaram-se as características físicas das infraestruturas existentes para atender aos modos de transportes NM a partir da relação dos pedestres, ciclistas e de pessoas com deficiências físicas com a facilidade de percorrer o caminho desejado (Microacessibilidade), observando os diferentes elementos visíveis e invisíveis, que podem interferir no conforto deste deslocamento.

O método utilizado, de avaliação denominado Nível de Serviço- NS, que, de acordo com VTPI (2010b), é uma ferramenta muito utilizada na identificação de problemas, estabelecimento de indicadores de desempenho, além de indicar possíveis soluções. A delimitação da área de estudo abrangeu uma área com extensão que variou entre $500 \mathrm{e}$ 600 metros de raio de alcance máximo, tendo a Estação da Lapa como eixo central, localizada no centro tradicional do Município de Salvador, e que representa uma das mais importantes estações de transbordo da cidade, com aproximadamente, 470.000 viagens/dia. A identificação de fatores que interferem no deslocamento NM foi feita através da análise de estudos relacionados ao desempenho do pedestre e/ou do ciclista no ambiente urbano das cidades, desde pesquisas bibliográficas, pesquisa sobre a percepção de indivíduos, opiniões de especialistas e demais fontes de investigação.

Alguns fatores identificados no estudo apresentaram uma importante relação de causa efeito com o conforto ambiental:

i. Design/projeto das vias para pedestres, ciclistas e pessoas com deficiência física;

ii. Declividade, correspondendo às condições de declividade favoráveis para $o$ desempenho dos deslocamentos; 
iii. Continuidade, ou seja, a sequência e continuidade no traçado das vias e percursos a pé, sem interrupções, favorecendo o conforto no deslocamento das pessoas.

Foram utilizadas para se estabelecer os critérios e parâmetros adequados na avaliação as normas técnicas ABNT NBR 12.255 NB 1338:1990, ABNT NBR 9050:2004.

Para as inspeções in loco da área de estudo, utilizou-se o sistema de classificação do Nível de Serviço que consiste na atribuição de pontuações estimadas dentro de uma determinada escala estabelecida pelo método, conforme Tabela 1, a seguir:

Tabela 1 - Parâmetros de pontuação do nível de serviço

\begin{tabular}{|c|c|c|c|c|c|c|c|}
\hline Nível de Serviço & A & B & C & D & E & F \\
Classificação & Excelente & Ótimo & Bom & Regular & Ruim & Péssimo \\
\hline Pontos & 5 & 4 & 3 & 2 & 1 & 0 \\
\hline Intervalos & 5 & 4,0 a 4,99 & 3,0 a 3,99 & 2,0 a 2,99 & 1,0 a 1,99 & 0,0 a 0,99 \\
\hline
\end{tabular}

Fonte: Paixão (2011)

Dentre a escala de pontuações estabelecidas, correspondente ao nível de serviço desempenhado na área, percebeu-se a predominância de condições regulares (classificação "D”), ou seja, que não possui os requisitos básicos necessários para se proporcionar espaços confortáveis para o desempenho dos deslocamentos NM (PAIXÃO, 2011). Em alguns trechos, a declividade influenciou muito na pontuação, visto que a própria Estação da Lapa encontra-se "encravada" em meio à cadeia de morros que a cerca, confirmando a interferência que o relevo oferece aos deslocamentos dos usuários da estação. Os trechos classificados com nível de serviço ruim (em cor vermelha) parecem formar "ilhas" de obstáculos em diversas direções da área de estudo, iniciando-se pela região mais próxima de acesso à Lapa onde constam pelo menos três trechos que podem ser considerados como críticos. Para melhor entendimento, segue a Figura 2:

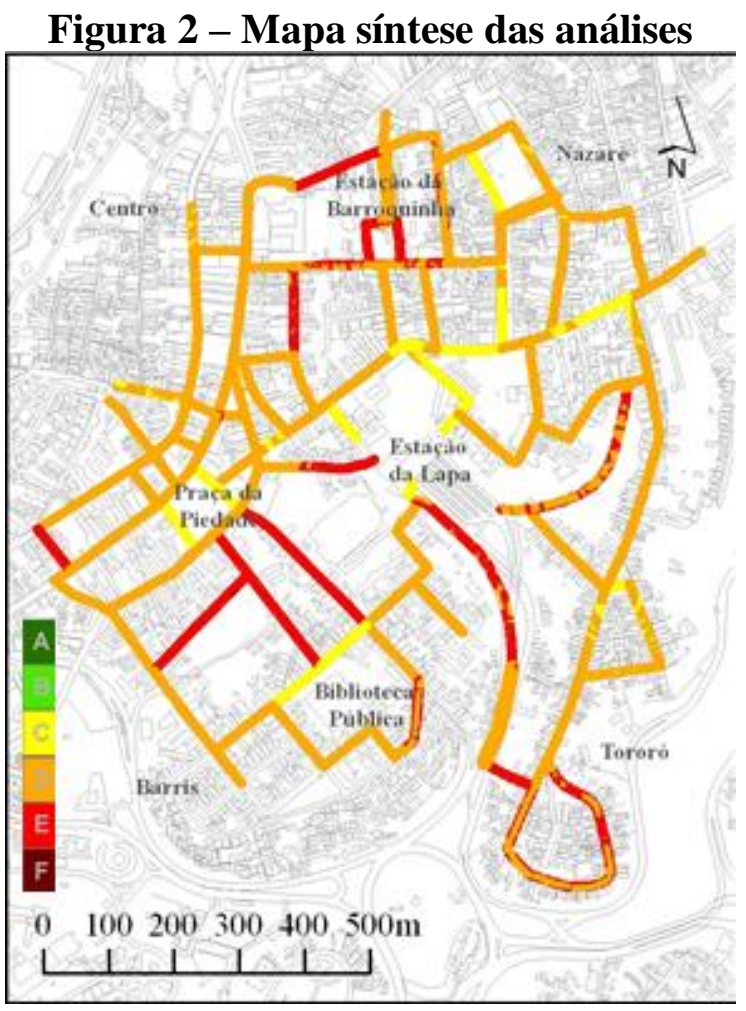

Fonte: Paixão (2011) 
Também foi observado sobre o quanto este assunto permeia a questão da saúde pública, pois, a falta de rotas adequadas para o deslocamento das pessoas determina o risco quanto à integridade física e até a vida dos indivíduos.

\section{DISCUSSÃO}

A degradação ambiental ocorre ao passo que a cidade se expande, especialmente pela falta de planejamento integrado entre construção e elementos da natureza. Para a finalidade do conforto térmico, considerando locais de clima quente, o porte arbóreo funciona como elemento redutor de radiação solar na superfície, reduzindo, inclusive, a temperatura do ar. O conforto térmico urbano não é previsto em leis municipais, ao passo que seria necessário para a garantia do equilíbrio térmico dos indivíduos no território construído.

Para alcançar resultados coerentes e pertinentes de mapeamento acústico, se faz imprescindível a adoção de uma base cartográfica atualizada. Desmistificando-se uma possível complexidade na confecção de mapas, não só especialistas em acústica urbana e mapeamento acústico seriam capazes de produzi-los, e com base georreferenciada atualizada.

As discussões que se seguiram ao conforto ergonômico foram baseadas na necessidade de se buscar mecanismos para atuação dos governantes, principalmente em âmbito municipal, já que se trata de situações que afetam a Cidade de Salvador e seus habitantes em geral, não esquecendo que esta responsabilidade também se estenderia ao morador, mantendo a calçada lindeira ao seu lote em bom estado e adequada para contribuir com o deslocamento NM confortável.

\section{CONSIDERAÇÕES FINAIS}

Diante dos resultados apresentados, que apontam para a insatisfação da população quanto aos confortos discutidos e pesquisados na Cidade de Salvador. Na avaliação do conforto térmico, pôde-se perceber a inadequada qualidade das áreas abertas urbanas pesquisadas para os horários da tarde, entre 14:00 e 15:00h, momento inicial das pesquisas de campo, onde o sol se encontra com alturas elevadas. Para o bloqueio da radiação solar incidente na superfície, nesses horários, seria a utilização vasta de porte arbóreo. As leis vigentes que regem o ordenamento e uso do solo não contemplam parâmetros que procurem regular o ambiente ao equilíbrio do balanço térmico humano; em verdade, as leis que regem a construção da cidade convergem para a intensificação da construção e esgotamento do solo, resultando em desertificação do território.

A partir de uma avaliação crítica dos mapas acústicos da região de estudo, no que toca aos níveis excedentes em relação a distintos parâmetros estabelecidos pela ABNT-NBR 10151 (ABNT, 2000) e Lei Municipal No 5.354 (SALVADOR, 1998), constatou-se que a análise a partir do parâmetro da referida norma, de abrangência nacional, aponta para um meio urbano mais poluído acusticamente que a análise a partir do parâmetro da lei municipal. A inexistência de leis ou planos estratégicos de mitigação do ruído proveniente do transporte rodoviário na referida cidade colabora para níveis insatisfatórios de ruído.

A relação da má qualidade de deslocamentos NM pode estar associada à priorização da condução do Poder Público em direcionar à atenção para os deslocamentos por automóveis, especialmente automóveis particulares. Por essa razão, em muitos trechos da cidade há inexistência de vias para o deslocamento NM, bem como a falta de manutenção com as vias existentes, ainda o total descaso para com os pedestres. 


\section{REFERÊNCIAS}

ASSOCIAÇÃO BRASILEIRA DE NORMAS TÉCNICAS (ABNT). NBR 12.255 NB 1338: Execução e utilização dos passeios. Rio de Janeiro, 1990.

. NBR 9050. Acessibilidade a edificações, mobiliário, espaços e equipamentos urbanos. Rio de Janeiro, 2004.

. NBR no 10151 Avaliação do ruído em áreas habitadas visando o conforto da comunidade. Rio de Janeiro, 2000.

BRASIL. Código de Trânsito Brasileiro e Legislação Complementar em Vigor, $1^{\mathrm{a}}$ edição. Brasília: DENATRAN, 2008.

CHANDLER, T. J., Urban climatology, inventory and prospect, in Urban climates. (Tech. note 108), WMO, Geneva, 1970.

INTERNATIONAL ORGANIZATION FOR STANDARDIZATION. Ergonomics of the Thermal Environment - Determination of Metabolic Rate. $2^{\text {a }}$ edition. Norma ISO 8996. Genebra, 2004.

PAIXÃO, R. C. da. Análise espacial das condições de deslocamento do pedestre na integração com o transporte público. 2011. 190 f. Dissertação (Mestrado em Engenharia Ambiental Urbana) - Escola Politécnica da Universidade Federal da Bahia, Salvador.

SALVADOR. Lei Municipal No 7.400, de 2008 - Dispõe sobre o Plano Diretor de DesenvolvimentoUrbano do Município do Salvador - PDDU 2007 e dá outras providências. Disponível em meio digital - CD Room. Prefeitura do Salvador, SEDHAM: Salvador, 2008.

SALVADOR. Lei Municipal N$^{\circ}$ 5.354, de 28 de janeiro de 1998. Dispõe sobre sons urbanos, fixa níveis e horários em que será permitida sua emissão, cria licença para utilização sonora e dá outras providências. 1998.

SOUZA, D. F. M. de. Mapeamento acústico do ruído de tráfego rodoviário do bairro Imbuí, Salvador-Ba. 2012. 368 f. Dissertação (Mestrado em Arquitetura e Urbanismo) Faculdade de Arquitetura da Universidade Federal da Bahia, Salvador.

SOUZA, S. H. M de. Avaliação do Desempenho Térmico nos Microclimas das Praças: Piedade e Visconde de Cayrú, Salvador/BA. 2010. 203 f. (Mestrado em Engenharia Ambiental Urbana) - Escola Politécnica da Universidade Federal da Bahia, Salvador.

VTPI. Nonmotorized Transportation Planning: Identifying ways to improve pedestrian and bicycle transport. British Columbia. nov. 2010a. Disponível em <http://www.vtpi.org/tdm/tdm25.htm>. Acesso em: 11 ago 2010.

VTPI. Multi-Modal Level-of-Service Indicators :Tools for evaluating the quality of transport services and facilities. British Columbia. nov. 2010b. Disponível em <http://www.vtpi.org/tdm/tdm129.htm>. Acesso em: 17 dez. 2010. 